\title{
Polyamine flux suppresses histone lysine demethylases and enhances IDI expression in cancer stem cells
}

\author{
Keisuke Tamari ${ }^{1,2,3}$, Masamitsu Konno ${ }^{2}$, Ayumu Asai ${ }^{2,3}$, Jun Koseki ${ }^{3}$, Kazuhiko Hayashi ${ }^{1,2,4}$, Koichi Kawamoto ${ }^{5}$, \\ Noriyuki Murai ${ }^{6}$, Senya Matsufuji ${ }^{6}$, Fumiaki Isohashi ${ }^{1}$, Taroh Satoh ${ }^{2}$, Noriko Goto ${ }^{7}$, Shinji Tanaka $\mathbb{C}^{8}$, Yuichiro Doki ${ }^{5}$, \\ Masaki Mori ${ }^{5}$, Kazuhiko Ogawa ${ }^{1}$ and Hideshi Ishii ${ }^{2,3}$
}

\begin{abstract}
Cancer stem cells (CSCS) exhibit tumorigenic potential and can generate resistance to chemotherapy and radiotherapy. A labeled ornithine decarboxylase (ODC, a rate-limiting enzyme involved in polyamine [PA] biosynthesis) degradation motif (degron) system allows visualization of a fraction of CSC-like cells in heterogeneous tumor populations. A labeled ODC degradation motif system allowed visualization of a fraction of CSC-like cells in heterogeneous tumor populations. Using this system, analysis of polyamine flux indicated that polyamine metabolism is active in CSCs. The results showed that intracellular polyamines inhibited the activity of histone lysine 4 demethylase enzymes, including lysine-specific demethylase-1 (LSD1). Chromatin immunoprecipitation with Pol II antibody followed by massively parallel DNA sequencing, revealed the global enrichment of Pol II in transcription start sites in CSCs. Increase of polyamines within cells resulted in an enhancement of ID1 gene expression. The results of this study reveal details of metabolic pathways that drive epigenetic control of cancer cell stemness and determine effective therapeutic targets in CSCs.
\end{abstract}

\section{Introduction}

Recent advances in understanding tumor heterogeneity have revealed the presence of subpopulations of highly tumorigenic cancer stem cells (CSCs) and weakly tumorigenic non-CSCs ${ }^{1}$. Compared with non-CSCs, CSCs possess tumorigenic, self-renewal, and multilineage differentiation potential and are resistant to chemotherapeutic agents and radiotherapy, so they cause treatment failure due to tumor recurrence and metastases ${ }^{1}$.

Correspondence: Kazuhiko Ogawa (kogawa@radonc.med.osaka-u.ac.jp) or Hideshi Ishii (hishii@gesurg.med.osaka-u.ac.jp)

'Department of Radiation Oncology, Osaka University Graduate School of Medicine, Osaka 565-0871, Japan

2Department of Frontier Science for Cancer and Chemotherapy, Osaka University Graduate School of Medicine, Osaka 565-0871, Japan

Full list of author information is available at the end of the article. These authors contributed equally: Keisuke Tamari, Masamitsu Konno Edited by I. Amelio
Researchers have studied differences between metabolic activities in CSCs and non-CSCs mainly through glucose metabolism ${ }^{2}$. Non-CSCs depend on glycolysis for survival and growth, whereas CSCs rely heavily on both glycolysis and oxidative phosphorylation (OXPHOS $)^{3,4}$. In addition, the biological behavior of cancer cells involves methylation of histones, RNA, and DNA, all of which are modulated epigenetically by $\mathrm{S}$-adenosylmethionine (SAM), a methyl-donating compound ${ }^{5}$. Locasale found that one-carbon metabolism, comprising three reactions (folate cycle, methionine cycle, and transsulfuration pathway), couples with SAM generation and fuels polyamine (PA) metabolism ${ }^{6}$. However, despite these and other studies, the differences between PA metabolism in CSCs and non-CSCs are not entirely understood. PAs include putrescine, spermidine, and spermine and play an essential role in cell proliferation, cell survival, and cancer progression ${ }^{7}$.

\section{(c) The Author(s) 2018}

(c) (i) Open Access This article is licensed under a Creative Commons Attribution 4.0 International License, which permits use, sharing, adaptation, distribution and reproduction cc) in any medium or format, as long as you give appropriate credit to the original author(s) and the source, provide a link to the Creative Commons license, and indicate if changes were made. The images or other third party material in this article are included in the article's Creative Commons license, unless indicated otherwise in a credit line to the material. If material is not included in the article's Creative Commons license and your intended use is not permitted by statutory regulation or exceeds the permitted use, you will need to obtain permission directly from the copyright holder. To view a copy of this license, visit http://creativecommons.org/licenses/by/4.0/. 
Ornithine decarboxylase (ODC), as a rate-limiting enzyme, converts ornithine to putrescine as the first step in intracellular PA biosynthesis ${ }^{7}$. ODC is degraded by proteasomes, depending on its unique degradation motif (degron) but independent of ubiquitylation ${ }^{8}$. A study of the Zoanthus sp. green fluorescent protein (ZsGreen)-degron ${ }^{\mathrm{ODC}}$ fusion system enables visualization of a small population of tumorigenic CSCs ${ }^{9}$.

The maintenance of CSC "stemness" and differentiation to non-CSCs is controlled by epigenetic mechanisms ${ }^{10-12}$. PAs work potentially as epigenetic regulators, and previous studies on PAs and histone acetylation have shown their involvement in transcription and gene expression control $^{13}$. PAs are positively charged molecules and thus can interact with negatively charged DNA and RNA ${ }^{14}$. Subsequent changes in the chromatin structure can affect gene transcription, cell proliferation, and cell differentiation, suggesting that PA flux plays a role in chromatin remodeling and cell proliferation.

Lysine-specific demethylase-1 (LSD1), a nuclear homolog of amine oxidases, demethylates histone H3 lysine $4(\mathrm{H} 3 \mathrm{~K} 4)$ to close chromatin for transcriptional silencing ${ }^{15}$. LSD1 is overexpressed in several cancers, such as bladder, lung, pancreatic, and cervical cancers and neuroblastoma ${ }^{16-20}$. Polyamine oxidase (PAOX) converts spermine to spermidine and spermidine to putrescine $^{7}$. The structure of PAOX's catalytic pocket resembles LSD1's enzyme pocket ${ }^{21,22}$. Many studies have been conducted to discover drugs targeting LSD1 using PA analogs ${ }^{23,24}$. However, it is still unclear how natural PAs inhibit LSD1, how they control epigenetics in CSCs, and what results from chromatin modification. We studied the effect of PA flux using the ZsGreen-degron ${ }^{\mathrm{ODC}}$ fusion system and demonstrated that PA flux increase in CSCs modulates LSD1 function and remodels the expression of stemness genes, such as ID1, which further augment the tumorigenic nature of CSCs.

\section{Results}

The critical role of the ODC protein and polyamine flow in CSCs

To construct the ZsGreen-degron ${ }^{\mathrm{ODC}}$ fusion system, we used retroviral-mediated gene transfer of the green fluorescent protein-fused ODC degron in cancer cells $^{9,25-27}$, enabling visualization of a CSC population as ZsGreen-positive cells (Fig. 1a). Immunoblots using an anti-ODC antibody showed that protein levels of ODC, spermidine/spermine N1-acetyltransferase (SAT1), and PAOX were high in CSCs in cervical cancer and osteosarcoma cell lines (see chemistry in Fig. $1 \mathrm{~b}$ and results in Fig. 1c, S1a). The expression of other PA-metabolizing enzymes, such as spermidine synthase (SRM) and spermine synthase (SMS), showed little difference between
CSCs and non-CSCs, as determined using specific antibodies (Fig. 1c, S1a). ODC messenger RNA (mRNA) expression levels determined by real-time quantitative polymerase chain reaction (Fig. 1d) were not high. This result is supported by previous studies indicating that ODC accumulates by suppression of ubiquitinindependent degradation in proteasomes ${ }^{9,25-27}$. The data suggest that CSCs express a high level of ODC protein because of slow degradation and not because of ODC production increase.

Out findings prompted us to investigate PA metabolism in a ZsGreen-positive CSC population of HeLa cells. We measured the concentration of cellular PAs by gas chromatography-mass spectrometry (GC-MS). The results showed a 1.9-fold increase in PA concentration ratios of CSCs/non-CSCs in putrescine $(p<0.01)$, a 1.9fold increase in spermidine $(p<0.01)$, and a 2.4 -fold increase in spermine $(p<0.01)$, suggesting that PA levels increased in CSCs compared with non-CSCs (Fig. 1e).

Next, we studied PA flux. CSCs and non-CSCs were starved extracellular PA in a medium supplemented with dialyzed serum, exposed to ${ }^{13} \mathrm{C}$-ornithine, and performed GC-MS. The results showed that ornithine-to-PA conversion within 120 min was faster in CSCs than in nonCSCs (Fig. 1f, g), whereas the concentration of spermine was higher in non-CSCs over $12 \mathrm{~h}$ after addition of ${ }^{13} \mathrm{C}$ ornithine to the culture (Fig. S1b). These results suggested that CSCs possess higher levels of cellular PAs, which are maintained by rapid conversion of ornithine to putrescine, spermidine, and spermine, as noted by early time stimulation after starvation; the results were consistent with a mathematical study of PA flow in $\mathrm{CSCs}^{28}$.

\section{Inhibition of LSD1 activity by polyamines}

We suspected that cellular PA increase induces a CSClike phenotype. Given that LSD1 plays an important role in stemness or pluripotency maintenance in human embryonic stem cells ${ }^{29}$, we assumed that PAs may inhibit LSD1 demethylase sites and modulate epigenetics, resulting in stem phenotype induction in cancer cells. Computational structure analysis performed to this end showed that PAs bind to the LSD1 demethylase site. Binding energies between the LSD1 demethylase site and PAs were $-32 \mathrm{kcal} / \mathrm{mol}$ for putrescine, $-45 \mathrm{kcal} / \mathrm{mol}$ for spermidine, and $-63 \mathrm{kcal} / \mathrm{mol}$ for spermine, suggesting that among all PAs, spermine has the strongest binding (Fig. 2a). The enzyme assay also showed that putrescine, spermidine, and spermine inhibit LSD1 activity at 1 and $5 \mathrm{mM}$ in a dose-dependent manner and that spermine is the strongest inhibitor (Fig. 2b). Examination of the cytotoxic effects of PAs showed that spermine is the most cytotoxic (Fig. S2a). These results suggested that PAs can inhibit LSD1 activity. In addition, further examination 


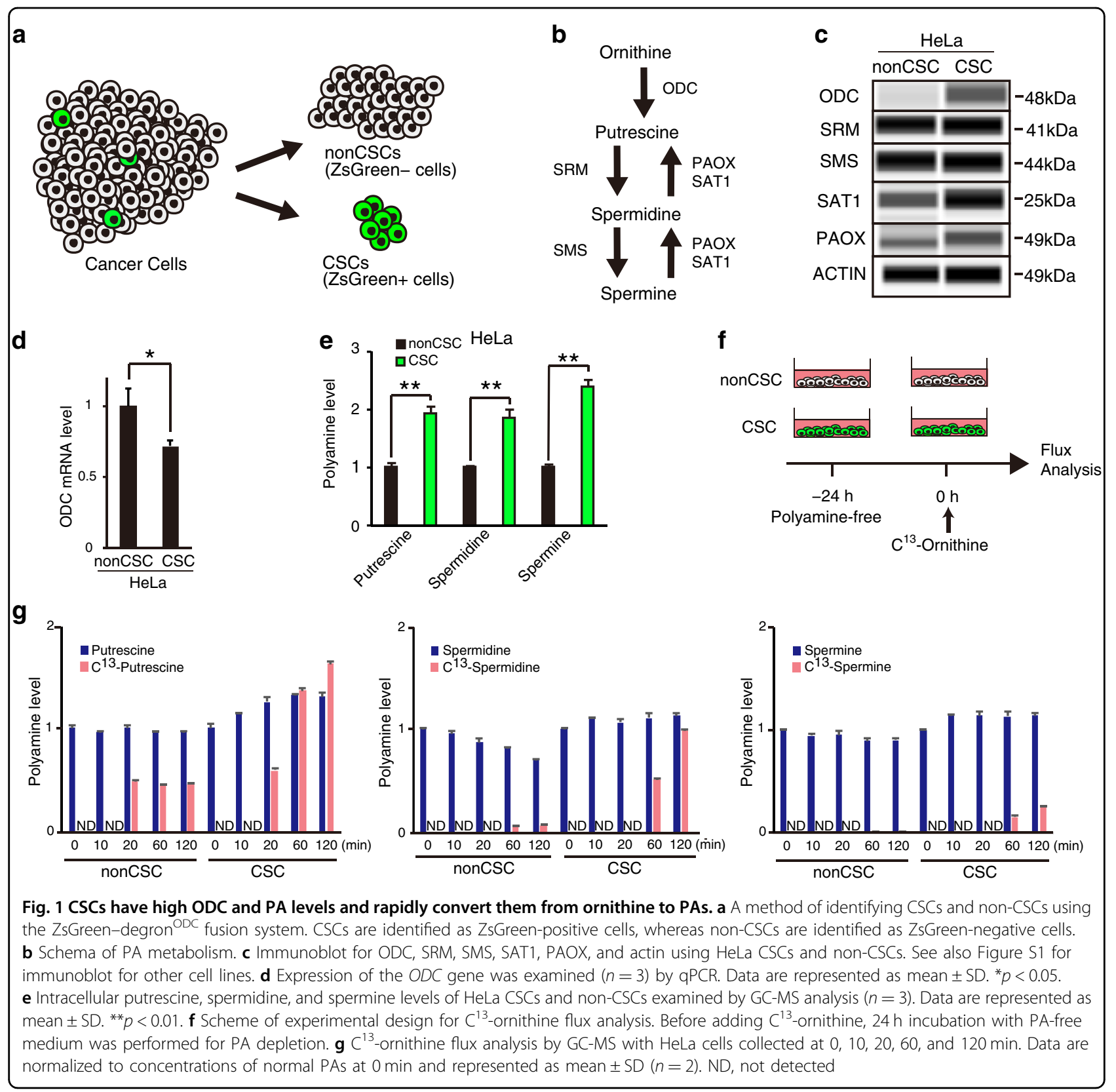

indicated that the demethylase activity of other histone demethylases, such as JMJD2A and KDM5B, is inhibited by PAs (Fig. S2b, c).

Next, we performed ChIP-Seq analysis of CSCs and non-CSCs in order to study polymerase II antibodies (Pol II) interactions across the entire genome. The results showed that Pol II is enriched in transcription start site (TSS) in CSCs compared with non-CSCs (Fig. 2c).

We concluded that PAs inhibit LSD1 activity and induce transcriptional modifications via epigenetic H3K4 demethylation.

\section{ID gene expression induction by polyamines}

To study the gene expression profile induced by cellular PA increase, we performed microarray analysis of HeLa cells exposed to putrescine and spermine. We used gene set enrichment analysis to interpret gene expression data and found that the gene set negative regulation of binding significantly changed in cells exposed to putrescine and spermine, including expression of inhibitors of differentiation, ID1, ID2, and ID3 (Fig. 3a, b). Previous reports indicate that ID family members play a role in promoting malignant biological phenotypes in cancer ${ }^{30}$. Consistent 


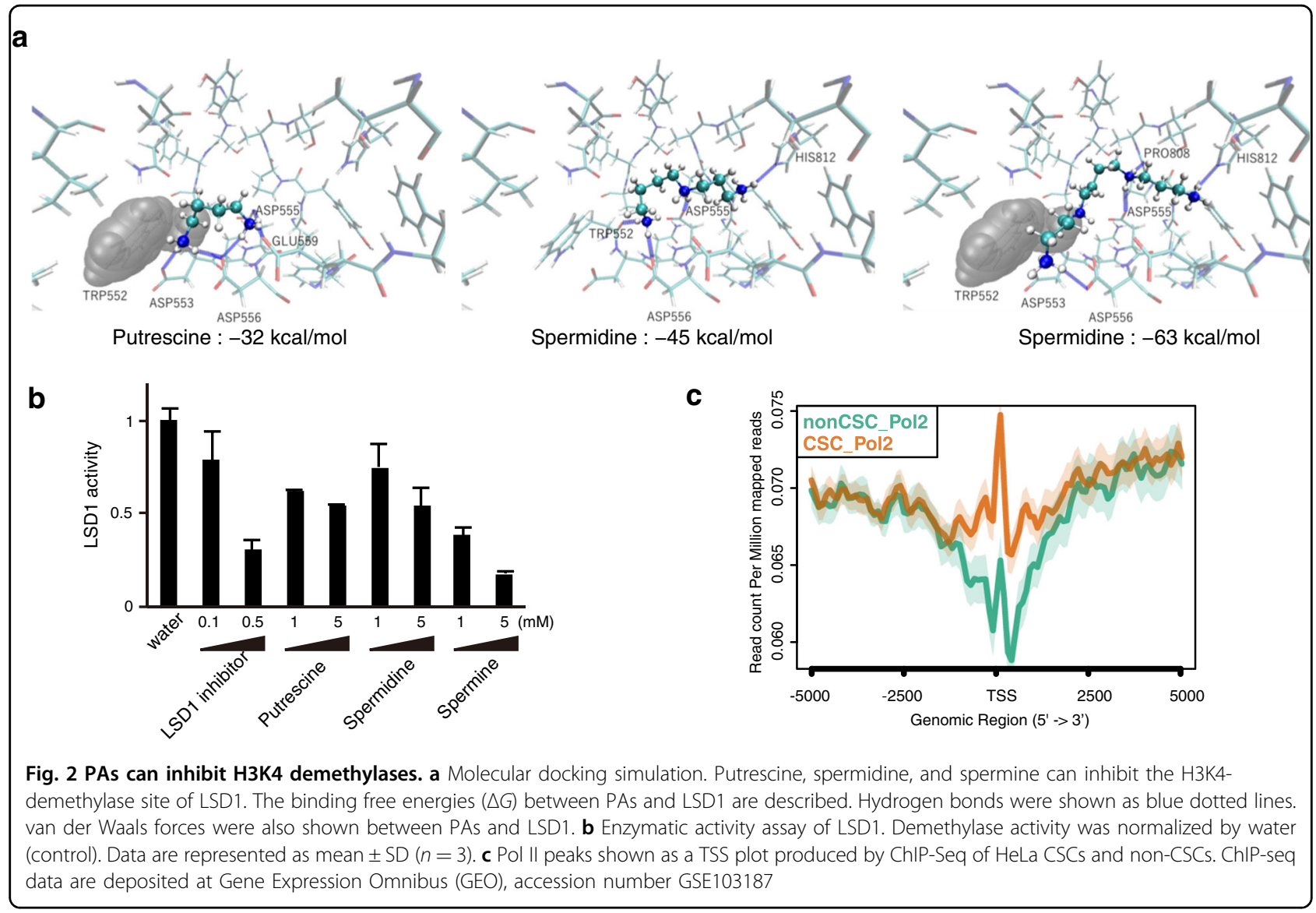

with earlier studies, this study indicated that PA increase is associated with up-regulation of $I D 1, I D 2$, and $I D 3$ mRNA expression and therefore inhibition of cancer cell differentiation.

\section{Overexpression and self-renewal induction of ID1 in CSCs}

Next, we examined $I D$ gene expression in the ZsGreen-degron ${ }^{\mathrm{ODC}}$ fusion system. The data indicated that ID1 is overexpressed in CSCs (Fig. 3c). To investigate the role of $I D 1$ in CSC-like phenotypes, we studied overexpression of ID1 in HeLa (HeLa-ID1-OE) cells. Both cell types showed higher sphere-forming capacity compared with control cells. However, studies of ID2 overexpression in HeLa cells showed higher sphere-forming capacity in ID2-OE cells than in control cells (Fig. 3d, e). These results suggested that the ID family has the potential to enhance cancer cell stemness.

\section{Epigenetic upregulation of ID genes by polyamines}

To confirm ID gene epigenetic regulation, we carried out ChIP-PCR of the ID gene promoter region by H3K4 methylation antibodies and LSD1 antibody. The results showed that an increase in PAs, especially putrescine, induces H3K4 methylation and inhibition of LSD1 binding of promoter regions (Fig. 4a). In addition, to examine whether LSD1 function decrease causes an increase in ID gene expression, we performed LSD1 knockdown in HeLa cells by small interfering RNA (siRNA), inducing ID gene expression (Fig. 5b). These results suggested that PAs, mainly putrescine, inhibit LSD1 function and stimulate high levels of methylated H3K4 in regulatory regions of ID gene expression.

\section{Discussion}

In this study, we showed that CSCs have a higher level of PAs compared with non-CSCs. The reason is presumably ODC function, as demonstrated by the pulsechase experiment, in which CSCs showed higher PA metabolism compared with non-CSCs, using the ZsGreen-degron ${ }^{\mathrm{ODC}}$ fusion system. Our results suggested that ODC protein levels are upregulated via a posttranscriptional mechanism. ODC is regulated via many processes, for example, ubiquitin-independent degradation by the $26 \mathrm{~S}$ proteasome and degradation by antizyme through frame-shift-dependent translational regulation ${ }^{31}$. Our hypothesis was that in CSCs, the PA production mechanism might be established in the ODC pathway, which was relevant to a CSC-like nature, as shown in our 

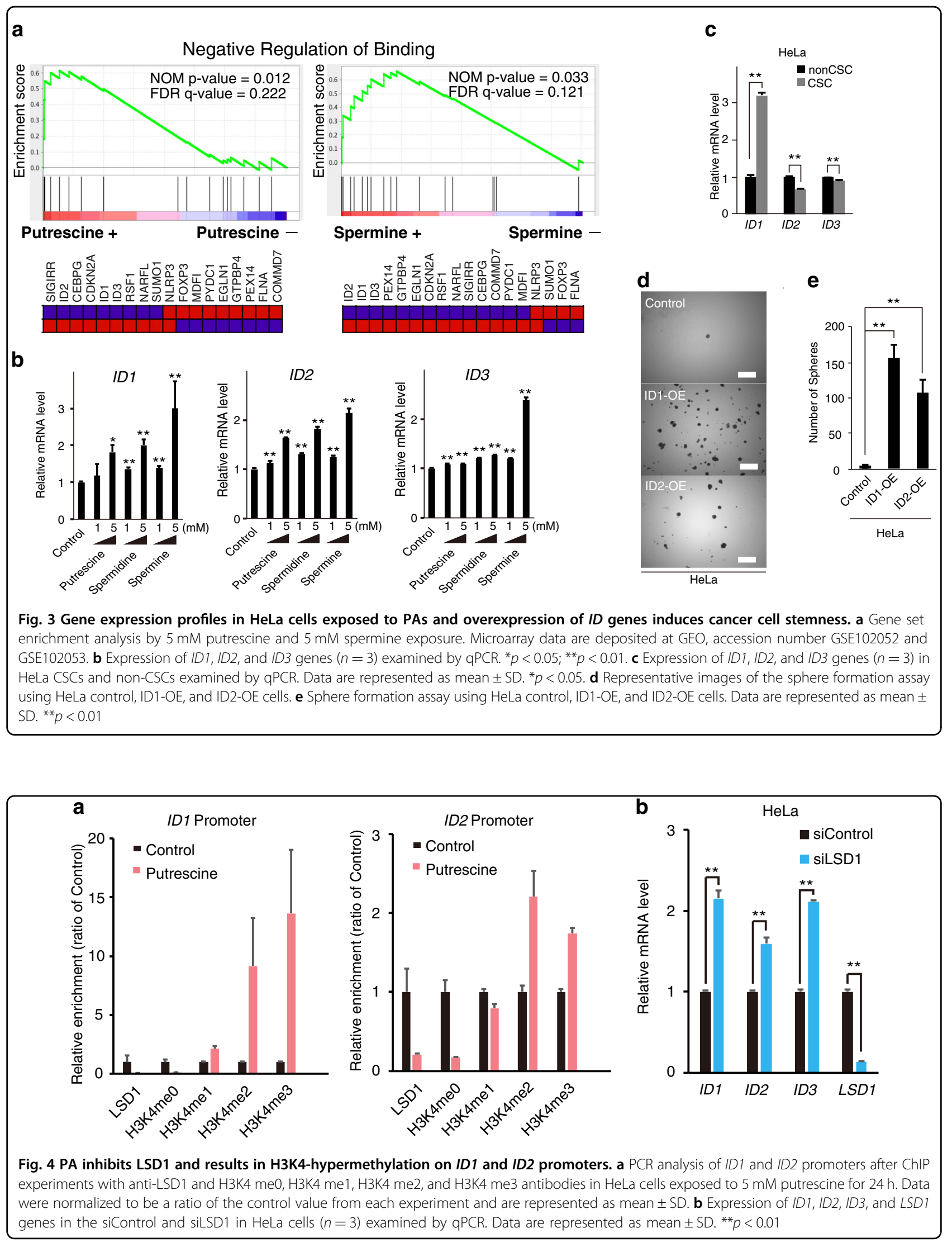
ZsGreen-degron ${ }^{\mathrm{ODC}}$ fusion system. To the best of our knowledge, ours is the first report on CSCs expressing substantial ODC levels and PAs. Intracellular PAs and ODC play a role in cancer progression ${ }^{7}$. For example, in hedgehog-dependent medulloblastoma, ODC and PA levels are elevated and pharmacological inhibition of PA axis efficiently blocks medulloblastoma cell proliferation $^{32}$. In some cancers with poor prognosis, ODC is overexpressed $^{33,34}$.

We showed that in the ZsGreen-degron ${ }^{\mathrm{ODC}}$ fusion system for CSC identification, increased PAs in CSCs inhibit H3K4-specific demethylases, such as LSD1 and JARID1B. It has been proposed that increased PAs act as antagonists to H3K4 enzymatic demethylation, which was more apparent in CSCs than in non-CSCs. As H3K4 methylation enhances transcriptional activation ${ }^{35}$, PAflux-induced LSD1 inhibition may contribute to induction of CSC-like phenotypes.

ID proteins are transcriptional regulators that control differentiation in stem and progenitor cells ${ }^{30}$. In cancer, ID proteins are induced by oncoproteins (e.g., MYC, RAS, SRC, Notch, EWS-FLI1, and receptor tyrosine kinases) and growth factor-directed signals (e.g., epidermal growth factor [EGF], basic fibroblast growth factor [bFGF], transforming growth factor- $\beta$, and bone morphogenetic proteins $)^{30}$. However, little is known about the epigenetic control of $I D$ genes with regard to histone modification. This study demonstrated that increased PA levels induce H3K4 methylation and trigger ID1 transcription in CSCs. Considering that high levels of ID protein expression in cancer cells are important, potential prognostic and diagnostic markers in several tumors, including breast, colorectal, liver, and prostate cancers ${ }^{36-39}$, the treatment strategy of targeting ID1 in CSCs is a promising way to cure cancer.

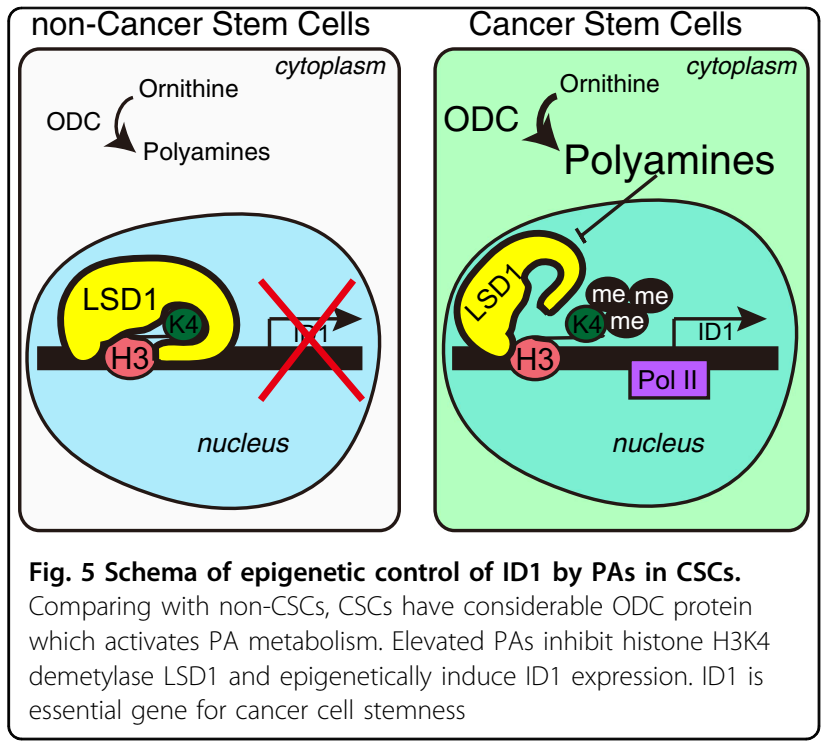

\section{Materials and methods \\ Cell culture}

Human cervical cancer cell lines (HeLa, CaSki, and ME180) and osteosarcoma cell lines (MG63 and U2OS) were purchased from the American Type Culture Collection (VA, USA) and were cultured in Dulbecco's modified Eagle's medium (DMEM) supplemented with $10 \%$ fetal bovine serum (FBS), $100 \mathrm{U} / \mathrm{mL}$ penicillin, and $100 \mu \mathrm{g} / \mathrm{mL}$ streptomycin.

\section{Stable cell lines}

The retroviral expression vector pQCXIN-ZsGreencODC, in which the C-terminal region (37 amino acids) of murine ornithine decarboxylase (termed "cODC" or "degron") was fused to ZsGreen, was used to visualize the CSC population as ZsGreen-positive cells. The proteasome sensor vector ZsProSensor-1 (632425, Clontech, CA, USA) encodes the gene for ZsGreen-cODC, and ZsGreen-cODC was digested with BglII and NotI from ZsProSensor-1 and cloned into pQCXIN (631514, Clontech).

To construct ID1 and ID2 overexpression vectors, ID1 and ID2 ORF sequences were amplified by PCR with the primers described in Table S1. Then, these PCR products were digested with NotI and XhoI and then cloned into pMXs-IRES-Neo.

To generate a retrovirus, each retroviral vector was transfected into platinum A (Plat-A, RV-102, Cell Biolabs) retroviral packaging cells using FuGENE 6 (E2691, Promega, WI, USA). After $24 \mathrm{~h}$ incubation, the virus collected from the Plat-A supernatant was used to infect osteosarcoma and cervical cancer cells. Stable transfectants were selected with $200 \mu \mathrm{g} / \mathrm{mL}$ of Geneticin (10131027, Thermo Fisher Scientific, MA, USA) in a culture medium for 2 weeks.

\section{Polyamine deprivation and exposure}

For PA deprivation, we used DMEM supplemented with 10\% dialyzed FBS (26400044, Thermo Fisher Scientific), $100 \mathrm{U} / \mathrm{mL}$ penicillin, and $100 \mu \mathrm{g} / \mathrm{mL}$ streptomycin. For PA exposure, 3 and $5 \mathrm{mM}$ putrescine (P5780, SigmaAldrich, MO, USA), spermidine (S0266, Sigma-Aldrich), and spermine (S4264, Sigma-Aldrich) were added directly to DMEM supplemented with $10 \%$ dialyzed FBS, $100 \mathrm{U} /$ $\mathrm{mL}$ penicillin, $100 \mu \mathrm{g} / \mathrm{mL}$ streptomycin, and $1 \mathrm{mM}$ aminoguanidine hydrochloride (396494, Sigma-Aldrich). Aminoguanidine was routinely added to inhibit serum amino-oxidases and prevent extracellular PAs toxicity due to reactive oxygen species (ROS) generation ${ }^{40}$

\section{Sphere formation assay}

Cells were plated separately, with 3000 cells on ultralow-attachment six-well plates (3471, Corning, NY, USA), and incubated in serum-free DMEM/F12 medium (11330032, Thermo Fisher Scientific) supplemented with 
20 ng/mL bFGF (F0291, Sigma-Aldrich), 20 ng/mL EGF (E9644, Sigma-Aldrich), and N-2 MAX media supplement (AR009, R\&D Systems, MN, USA). After 14 days, spheres with diameters $>100 \mu \mathrm{m}$ were counted.

\section{Quantification of intracellular polyamines}

We sorted one million non-CSCs and CSCs by fluorescence-activated cell sorting (FACS) and centrifuged at $1000 \times g$ for $10 \mathrm{~min}$ at $4{ }^{\circ} \mathrm{C}$. Cell pellets were washed twice with phosphate-buffered saline (PBS). The washed pellets were homogenized on ice with $10 \% \mathrm{NaCl}$ solution at $\mathrm{pH} 1$ with $\mathrm{HCl}$ and then centrifuged at $12,000 \times g$ for $15 \mathrm{~min}$ at $4{ }^{\circ} \mathrm{C}$. The supernatant was extracted with $3 \mathrm{~mL}$ of diethyl ether by vortexing for 10 min and separated by centrifugation at $12,000 \times g$ for 20 $\mathrm{min}$, and the aqueous phases were collected. For Nethoxycarbonylation of the amines, $1 \mathrm{~mL}$ of diethyl ether containing $50 \mu \mathrm{L}$ of ethyl chloroformate was added to the sample solution. The reaction mixture was shaken at $23^{\circ}$ $\mathrm{C}$ for $30 \mathrm{~min}$ and centrifuged at $1200 \times g$ for $5 \mathrm{~min}$. The ether layer containing PA N-ethoxylcarbonyl (N-EOC) derivatives was transferred to a separate glass vial. This derivatization reaction was repeated by re-extracting the aqueous phase. The ether layers from the two extractions were combined and evaporated to complete dryness under a dry nitrogen stream. The dried PA N-EOC derivatives were put in $100 \mu \mathrm{L}$ of ethyl acetate, to which $200 \mu \mathrm{L}$ of trifluoroacetic anhydride was added. The sealed vials containing the mixture were placed on a $75^{\circ} \mathrm{C}$ heating block for $1 \mathrm{~h}$ to complete the trifluoroacetylation. The mixture was then evaporated to complete dryness under a dry nitrogen stream. The derivatives were reconstituted in $200 \mu \mathrm{L}$ of ethyl acetate, and $2 \mu \mathrm{L}$ of aliquots were injected for GC-MS analysis in triplicate.

\section{Molecular docking simulation}

To predict the PA docking poses, we performed docking simulations with Glide $^{41}$ in Schrodinger Suite 2009 (Schrödinger, LLC, NY, USA). The binding poses for ornithine, putrescine, spermidine, and spermine were generated in Glide SP (standard precision) mode. The binding free energy $(\Delta G)$ for each pose was estimated with the molecular mechanics energies combined with the generalized Born and surface area continuum solvation (MM/GBSA) method using Prime ${ }^{42}$ in Schrodinger Suite 2009 (Schrödinger, LLC). For each ligand, we selected binding poses with the lowest MM/GBSA score. In the docking simulations, we took the LSD1 protein coordinate (PDB ID: 2H94) from the Protein Data Bank (PDB).

\section{Histone demethylase inhibition assays}

For LSD1 and JMJD2A, we performed assays with 96well plates. We added $120 \mu \mathrm{L}$ of Enzyme Assay Buffer, 20 $\mu \mathrm{L}$ of LSD1 (or JMJD2A), $20 \mu \mathrm{L}$ of horseradish peroxidase
(HRP), $10 \mu \mathrm{L}$ of fluorometric substrate, and $10 \mu \mathrm{L}$ of solvent for $100 \%$ initial activity wells (positive control); 140 $\mu \mathrm{L}$ of Assay Buffer, $20 \mu \mathrm{L}$ of LSD1 (or JMJD2A), $20 \mu \mathrm{L}$ of $\mathrm{HRP}, 10 \mu \mathrm{L}$ of fluorometric substrate, and $10 \mu \mathrm{L}$ of solvent for background wells (negative control); and $120 \mu \mathrm{L}$ of Assay Buffer, $20 \mu \mathrm{L}$ of LSD1 (or JMJD2A), $20 \mu \mathrm{L}$ of HRP, $10 \mu \mathrm{L}$ of fluorometric substrate, and $10 \mu \mathrm{L}$ of LSD1 inhibitor and PA solution for inhibitor wells. Then, we added $20 \mu \mathrm{L}$ of peptide to all the wells, except background wells, incubated them for $30 \mathrm{~min}$ at $37^{\circ} \mathrm{C}$, and read the plates using an excitation wavelength of $530-540 \mathrm{~nm}$ and an emission wavelength of 585-595 nm.

For KDM5B, we performed the assay with 384-well plates. We added $2.5 \mu \mathrm{L}$ of $4 \times$ HDM Assay Buffer, $3 \mu \mathrm{L}$ of KDM5B, $1 \mu \mathrm{L}$ of biotinylated substrate, $0.5 \mu \mathrm{L}$ of water, and $3 \mu \mathrm{L}$ of inhibitor buffer for $100 \%$ initial activity wells (positive control); $2.5 \mu \mathrm{L}$ of $4 \times \mathrm{HDM}$ Incomplete Assay Buffer, $3 \mu \mathrm{L}$ of KDM5B, $1 \mu \mathrm{L}$ of biotinylated substrate, 0.5 $\mu \mathrm{L}$ of water, and $3 \mu \mathrm{L}$ of inhibitor buffer for background wells (negative control); and $2.5 \mu \mathrm{L}$ of $4 \times \mathrm{HDM}$ Assay Buffer, $3 \mu \mathrm{L}$ of KDM5B, $1 \mu \mathrm{L}$ of biotinylated substrate, 0.5 $\mu \mathrm{L}$ of water, $3 \mu \mathrm{L}$ of inhibitor buffer, and $3 \mu \mathrm{L}$ of PA solution for inhibitor wells. Then, we added $5 \mu \mathrm{L}$ of Eulabeled $\mathrm{K} 4$ antibody to all the wells and incubated them for $30 \mathrm{~min}$ at $23^{\circ} \mathrm{C}$, added $5 \mu \mathrm{L}$ of dye-labeled acceptor to all the wells, and incubated them again for $1 \mathrm{~h}$ at $23^{\circ} \mathrm{C}$ with shaking. Finally, we measured the fluorescent intensity at wavelengths of 620 and $665 \mathrm{~nm}$ in a microtiter-plate reader.

\section{Gene set enrichment analysis}

We used gene set enrichment analysis to interpret gene expression data, as previously described ${ }^{43}$.

\section{Quantitative RT-PCR}

Total RNA samples were extracted using ISOGEN reagent (311-02501, NIPPON GENE, Japan). To synthesize complementary DNA (cDNA), we used ReverTra Ace real-time quantitative polymerase chain reaction (RTqPCR) Master Mix with genomic DNA remover (FSQ301, Toyobo, Japan). We incubated $0.5 \mu$ g of total RNA for $5 \mathrm{~min}$ at $65^{\circ} \mathrm{C}$, mixed it with $4 \times \mathrm{DN}$ Master Mix, and incubated it for $5 \mathrm{~min}$ at $37^{\circ} \mathrm{C}$. Finally, we mixed $5 \times \mathrm{RT}$ Master Mix II and then incubated the mixture for $15 \mathrm{~min}$ at $37^{\circ} \mathrm{C}, 5 \mathrm{~min}$ at $50^{\circ} \mathrm{C}$, and $5 \mathrm{~min}$ at $98^{\circ} \mathrm{C}$ to obtain cDNA.

We performed RT-qPCR using LightCycler FastStart DNA Master SYBR Green I (12239264001, Roche Diagnostics, Mannheim, Germany) on a LightCycler 2.0 (Roche Diagnostics) according to the manufacturer's instructions. We gently mixed $9.4 \mu \mathrm{L}$ of water, $1.6 \mu \mathrm{L}$ of LightCycler FastStart DNA Master SYBR Green I, $1 \mu \mathrm{L}$ of forward primer $(10 \mu \mathrm{M})$, and $1 \mu \mathrm{L}$ of reverse primer $(10$ $\mu \mathrm{M})$ by pipetting and then added $2 \mu \mathrm{L}$ of cDNA. The 
mixture was transferred to a LightCycler capillary. PCR was performed by initial denaturation for $10 \mathrm{~min}$ at $95^{\circ} \mathrm{C}$, 45 -cycle quantification (denaturation for $10 \mathrm{~s}$ at $95^{\circ} \mathrm{C}$, annealing for $10 \mathrm{~s}$ at $55-60^{\circ} \mathrm{C}$, and extension for $10 \mathrm{~s}$ at $72{ }^{\circ} \mathrm{C}$ ), and melting curve (denaturation for $0 \mathrm{~s}$ at $95^{\circ} \mathrm{C}$, annealing for $15 \mathrm{~s}$ at $65^{\circ} \mathrm{C}$, and extension for $0 \mathrm{~s}$ at $72^{\circ} \mathrm{C}$ ). Primer sequences are listed in Table S1.

\section{SiRNA}

HeLa cells were seeded in 6-well plates $\left(4.0 \times 10^{5}\right.$ cells/ well) and transfected with $10 \mathrm{nM}$ small interfering RNAs (siRNAs) in the presence of Lipofectamine RNAiMAX (13778150, Thermo Fisher Scientific). The following siRNAs were used: siLSD1 (SASI_Hs01_00213078, SigmaAldrich), sixCT\#1 (SASI_Hs02_00345461, SigmaAldrich), sixCT\#2 (SASI_Hs01_00158008, SigmaAldrich), and a negative control (SIC-001-5, SigmaAldrich).

\section{Immunoblotting}

Sorted CSCs and non-CSCs were centrifuged, the supernatant discarded, and the cells washed with PBS twice. Radioimmunoprecipitation assay lysis buffer (89900, Thermo Fisher Scientific; $25 \mathrm{mM}$ Tris $\bullet \mathrm{HCl} \mathrm{pH}$ 7.6, $150 \mathrm{mM} \mathrm{NaCl}, 1 \% \mathrm{NP}-40,1 \%$ sodium deoxycholate, $0.1 \%$ sodium dodecyl sulfate) containing a protease inhibitor cocktail and phosphatase inhibitors was used to extract total protein samples from cell pellets. For ODC, spermidine synthase (SRM), spermine synthase (SMS), spermidine/spermine N1-acetyltransferase (SAT1), polyamine oxidase (PAOX), and $\beta$-actin, a WES capillary Western system (12-230 kD Master kit $\alpha$-Rabbit-HRP; PS-MK01; Protein Simple) was performed following instructions in the ProteinSimple user manual. In brief, protein samples were diluted with $0.1 \times$ Sample Buffer to the concentration of $1.25 \mathrm{mg} / \mathrm{mL}$. Protein samples and $5 \mathrm{x}$ Fluorescent Master Mix were mixed in a micro-centrifuge tube and heated at $95^{\circ} \mathrm{C}$ for $5 \mathrm{~min}$. After denaturation step, the samples, blocking reagent, primary antibodies (1:50 anti-ODC1 (ab97395, Abcam), 1:50 anti-SMS (HPA029852, Sigma-Aldrich), 1:50 anti-SRM (ABF257, Merck Millipore, Germany), 1:50 anti-SAT1 (ab105220, Abcam), 1:50 anti-PAOX (ab75119, Abcam), and 1:50 anti- $\beta$-actin (4967, CST, MA, USA), HRP-conjugated secondary antibodies and chemiluminescent substrate were dispensed into designated wells in an assay plate. A biotinylated ladder provided molecular weight standards for each assay. The data were analyzed using Compass software (Protein Simple).

\section{Chromatin immunoprecipitation}

Chromatin samples were prepared by Auto iDeal chromatin immunoprecipitation sequencing (ChIP-Seq) kit for histones (C01010171, Diagenode, NJ, USA).
Chromatin shearing was performed using Covaris S220 (Covaris Inc., MA, USA) in order to optimize the fragment size around 300 base pairs under the following conditions: $2 \%$ duty cycle, peak incident power of 105,200 cycles per burst, and a $12 \mathrm{~min}$ program at $4{ }^{\circ} \mathrm{C}$. Immunoprecipitation was performed using an SX-8G compact (Diagenode) with a direct ChIP mode. Polymerase II antibodies (ab5131, 1/50, Abcam, MA, USA) were used.

\section{ChIP-Seq data analysis}

FASTQ sequences were aligned to the human hg19 genome sequence using Bowtie $2^{44}$ and converted to sequence alignment map (SAM) and then binary alignment map files. Then, ChIP-Seq peaks were identified using MACS1.4 ${ }^{45}$. Transcription start site (TSS) plots were generated using ngsplot (https:/github.com/ shenlab-sinai/ngsplot). The Bowtie-aligned peaks and model-based analysis of ChIP-Seq (MACS)-determined peak positions were visualized using Integrative Genomics Viewer ${ }^{46}$.

\section{Quantification and statistical analysis}

Differences between groups were presented as mean $\pm \mathrm{SD}$, as noted in the figures. Experimental sample numbers are indicated in the figures. Data were analyzed using Student's $t$ test for two groups. $p<0.05$ was considered statistically significant.

\section{Accession numbers}

The Gene Expression Omnibus accession numbers reported in this paper are GSE102052, GSE102053, and GSE103187.

\section{Acknowledgements}

We thank laboratory staffs for their helpful discussion. This work received financial support partially from grants-in-aid for Scientific Research from the Ministry of Education, Culture, Sports, Science, and Technology (grant nos. 17H04282, 17K19698, 16K15615, and 15H057919) and Taiho Pharmaceutical Co., Ltd. (to J.K., M.M., and H.I.).

\section{Author details \\ 'Department of Radiation Oncology, Osaka University Graduate School of Medicine, Osaka 565-0871, Japan. ${ }^{2}$ Department of Frontier Science for Cancer and Chemotherapy, Osaka University Graduate School of Medicine, Osaka 565- 0871, Japan. ${ }^{3}$ Department of Medical Data Science, Osaka University Graduate School of Medicine, Osaka 565-0871, Japan. ${ }^{4}$ Division of Hospital, National Institute of Radiological Sciences, Chiba 263-8555, Japan. ${ }^{5}$ Department of Gastroenterological Surgery, Osaka University Graduate School of Medicine, Osaka 565-0871, Japan. 'Department of Molecular Biology, Jikei University School of Medicine, Tokyo 105-8461, Japan. ${ }^{7}$ Cancer Research Institute, Kanazawa University, Kanazawa 920-1192, Japan. ${ }^{8}$ Department of Molecular Oncology, Tokyo Medical and Dental University, Tokyo 113-8510, Japan}

\section{Conflict of interest}

Institutional endowments were received from Taiho Pharmaceutical Co., Ltd. (Tokyo, Japan), Evidence Based Medical Research Center Inc. (Osaka, Japan), UNITECH Co., Ltd. (Chiba, Japan), IDEA Consultants, Inc. (Tokyo, Japan), and Kinshu-kai Medical Corporation (Osaka, Japan). 


\section{Publisher's note}

Springer Nature remains neutral with regard to jurisdictional claims in published maps and institutional affiliations.

The online version of this article (https://doi.org/10.1038/s41420-018-0117-7) contains supplementary material, which is available to authorized users.

\section{Received: 3 September 2018 Revised: 9 October 2018 Accepted: 16 October 2018 \\ Published online: 13 November 2018}

\section{References}

1. Kreso, A. \& Dick, J. E. Evolution of the cancer stem cell model. Cell Stem Cell 14, 275-291 (2014).

2. Peiris-Pagès, M., Martinez-Outschoorn, U. E., Pestell, R. G., Sotgia, F. \& Lisanti, M. P. Cancer stem cell metabolism. Breast Cancer Res. 18, 1-10 (2016).

3. Shen, Y.-A., Wang, C.-Y., Hsieh, Y.-T., Chen, Y.-J. \& Wei, Y.-H. Metabolic reprogramming orchestrates cancer stem cell properties in nasopharyngeal carcinoma. Cell Cycle 14, 86-98 (2015).

4. Chen, C. L. et al. NANOG metabolically reprograms tumor-initiating stem-like cells through tumorigenic changes in oxidative phosphorylation and fatty acid metabolism. Cell Metab. 23, 206-219 (2016).

5. Wong, C. C., Qian, Y. \& Yu, J. Interplay between epigenetics and metabolism in oncogenesis: mechanisms and therapeutic approaches. Oncogene 36, 3359-3374 (2017)

6. Locasale, J. W. Serine, glycine and one-carbon units: cancer metabolism in full circle. Nat. Rev. Cancer 13, 572-583 (2013).

7. Gerner, E. W. \& Meyskens, F. L. Polyamines and cancer: old molecules, new understanding. Nat. Rev. Cancer 4, 781-792 (2004).

8. Murakami, Y. et al. Ornithine decarboxylase is degraded by the $26 \mathrm{~S}$ proteasome without ubiquitination. Nature 360, 597-599 (1992).

9. Vlashi, E. et al. In vivo imaging, tracking, and targeting of cancer stem cells. J. Natl Cancer Inst. 101, 350-359 (2009).

10. Rheinbay, E. et al. An aberrant transcription factor network essential for Wnt signaling and stem cell maintenance in glioblastoma. Cell Rep. 3, 1567-1579 (2013).

11. Yamazaki, J. et al. The epigenome of AML stem and progenitor cells. Epigenetics 8, 92-104 (2013).

12. Wong, S. H. K. et al. The H3K4-methyl epigenome regulates leukemia stem cell oncogenic potential. Cancer Cell 28, 198-209 (2015).

13. Hobbs, C. A. \& Gilmour, S. K. High levels of intracellular polyamines promote histone acetyltransferase activity resulting in chromatin hyperacetylation. J. Cell Biochem. 77, 345-360 (2000).

14. Watanabe, S. I., Kusama-Eguchi, K., Kobayashi, H. \& Igarashi, K. Estimation of polyamine binding to macromolecules and ATP in bovine lymphocytes and rat liver. J. Biol. Chem. 266, 20803-20809 (1991).

15. Shi, Y. et al. Histone demethylation mediated by the nuclear amine oxidase homolog LSD1. Cell 119, 941-953 (2004).

16. Kahl, P. et al. Androgen receptor coactivators lysine-specific histone demethylase 1 and four and a half LIM domain protein 2 predict risk of prostate cancer recurrence. Cancer Res. 66, 11341-11347 (2006).

17. Liu, Y. et al. LSD1 binds to HPV16 E7 and promotes the epithelialmesenchymal transition in cervical cancer by demethylating histones at the Vimentin promoter. Oncotarget 8, 11329-11342 (2017).

18. Qin, Y. et al. LSD1 sustains pancreatic cancer growth via maintaining HIF1adependent glycolytic process. Cancer Lett. 347, 225-232 (2014).

19. LV, T. et al. Over-expression of LSD1 promotes proliferation, migration and invasion in non-small cell lung cancer. PLoS ONE 7, e35065 (2012).

20. Schulte, J. H. et al. Lysine-specific demethylase 1 is strongly expressed in poorly differentiated neuroblastoma: implications for therapy. Cancer Res. 69, 2065-2071 (2009).

21. Stavropoulos, P., Blobel, G. \& Hoelz, A. Crystal structure and mechanism of human lysine-specific demethylase-1. Nat. Struct. Mol. Biol. 13, 626-632 (2006).
22. Chen, Y. et al. Crystal structure of human histone lysine-specific demethylase 1 (LSD1). Proc. Natl Acad. Sci. USA 103, 13956-13961 (2006).

23. Huang, $Y$. et al. Inhibition of lysine-specific demethylase 1 by polyamine analogues results in reexpression of aberrantly silenced genes. Proc. Natl Acad. Sci. USA 104, 8023-8028 (2007).

24. Mohammad, H. P. et al. A DNA hypomethylation signature predicts antitumor activity of LSD1 Inhibitors in SCLC. Cancer Cell 28, 57-69 (2015).

25. Adikrisna, R. et al. Identification of pancreatic cancer stem cells and selective toxicity of chemotherapeutic agents. Gastroenterology 143, 234-245. e7 (2012).

26. Hayashi, K. et al. Visualization and characterization of cancer stem-like cells in cervical cancer. Int. J. Oncol. 45, 2468-2474 (2014).

27. Tamari, $\mathrm{K}$. et al. Identification of chemoradiation-resistant osteosarcoma stem cells using an imaging system for proteasome activity. Int. J. Oncol. 45, 2349-2354 (2014)

28. Koseki, J. et al. A Trans-omics mathematical analysis reveals novel functions of the ornithine metabolic pathway in cancer stem cells. Sci. Rep. 6, 20726 (2016).

29. Yin, F. et al. LSD1 regulates pluripotency of embryonic stem/carcinoma cells through histone deacetylase 1-mediated deacetylation of histone $\mathrm{H} 4$ at lysine 16. Mol. Cell Biol. 34, 158-179 (2014).

30. Lasorella, A., Benezra, R. \& lavarone, A. The ID proteins: master regulators of cancer stem cells and tumour aggressiveness. Nat. Rev. Cancer 14, 77-91 (2014).

31. Coffino, P. Regulation of cellular polyamines by antizyme. Nat. Rev. Mol. Cell Biol. 2, 188-194 (2001)

32. D'Amico, D. et al. Non-canonical Hedgehog/AMPK-mediated control of polyamine metabolism supports neuronal and medulloblastoma cell growth. Dev. Cell 35, 21-35 (2015).

33. Geerts, D. et al. The polyamine metabolism genes ornithine decarboxylase and antizyme 2 predict aggressive behavior in neuroblastomas with and without MYCN amplification. Int. J. Cancer 126, 2012-2024 (2010).

34. Manni, A., Mauger, D., Gimotty, P. \& Badger, B. Prognostic influence on survival of increased ornithine decarboxylase activity in human breast cancer. Clin. Cancer Res. 2, 1901-1906 (1996).

35. Calo, E. \& Wysocka, J. Modification of Enhancer Chromatin: What, How, and Why? Mol. Cell 49, 825-837 (2013).

36. Matsuda, Y. et al. Overexpressed Id-1 is associated with a high risk of hepatocellular carcinoma development in patients with cirrhosis without transcriptional repression ofp16. Cancer 104, 1037-1044 (2005).

37. Coppe, J., Itahana, Y., Moore, D. H., Bennington, J. L. \& Desprez, P. Id-1 and Id-2 proteins as molecular markers for human prostate cancer progression. Clin. Cancer Res. 10, 2044-2051 (2004).

38. Minn, A. J. et al. Genes that mediate breast cancer metastasis to lung. Nature 436, 518-524 (2005).

39. O'Brien, C. A. et al. ID1 and ID3 regulate the self-renewal capacity of human colon cancer-initiating cells through p21. Cancer Cell 21, 777-792 (2012).

40. Perez-Leal, O., Barrero, C. A., Clarkson, A. B., Casero, R. A. \& Merali, S. Polyamineregulated translation of spermidine/spermine-N1-acetyltransferase. Mol. Cell Biol. 32, 1453-1467 (2012).

41. Friesner, R. A. et al. Extra precision glide: docking and scoring incorporating a model of hydrophobic enclosure for protein-ligand complexes. J. Med. Chem. 49, 6177-6196 (2006).

42. Jacobson, M. P. et al. A hierarchical approach to all-atom protein loop prediction. Proteins 55, 351-367 (2004).

43. Subramanian, A. et al. Gene set enrichment analysis: a knowledge-based approach for interpreting genome-wide expression profiles. Proc. Natl Acad. Sci. USA 102, 15545-1550 (2005).

44. Langmead, B. \& Salzberg, S. L. Fast gapped-read alignment with Bowtie 2. Nat. Methods 9, 357-359 (2012).

45. Zhang, Y. et al. Model-based analysis of ChIP-Seq (MACS). Genome Biol. 9, R137 (2008).

46. Robinson, J. T. et al. Integrative genomics viewer. Nat. Biotechnol. 29, 24-26 (2011). 